\title{
Evaluation of a Country's Sustainable Development
}

\author{
Zhanxi Zhang ${ }^{1, a}$ \\ ${ }^{1}$ School of North China Electric Power University, Baoding 071003, China \\ a18330212961@163.com
}

Keywords: sustainable development, sustainable indexes, GA-BP Neural Network Model

\begin{abstract}
We build the GA-BP Neural Network Model to evaluate the sustainability of the country. First we select nine indexes from natural resources, economic strength, human resources and social living environment in total, establish the index system for sustainable development and validate its completeness and independence among indexes. We randomly select ten countries as the sample data and define a mathematical standard for sustainability. We selected Nepal as a sample country to evaluate our model. First we determine trends of the indexes and use Regression Analysis Prediction Method (RAPM) to predict index value for twenty years. Our model's result indicates that the sustainability of Nepal is poor and the growth speed is low. Then we draw up a 20-year plan for Nepal's development. Compared with the result of no-plan, the sustainability of Nepal grows faster. According to the prediction, Nepal will become a sustainable country in about 2030.
\end{abstract}

\section{Introduction}

The United Nations (UN) predicts the world's population will level at 9 billion people by 2050. This, coupled with increased consumption, places a significant strain on the earth's finite resources. Therefore, one of the largest challenges and objectives of our time is how to manage increasing population and consumption with the earth's finite resources, that is to say, we must take the path of sustainable development.

There are many ways for evaluating a country's level of sustainable development. Few methods can give a specific response measures and predict the results of measures. For the above reasons, we build the GA-BP Neural Network Model to evaluate the sustainability of the country. We chose Nepal from the sample counties and give a list of specific improvement plans, then evaluated its effectiveness and verify its reasonableness and accuracy.

\section{Model Building}

Indexes selecting. Based on the wealth of our country [1], we propose a sustainability evaluation system. The system takes the natural resources, the current economic strengths, human resources and social living environment of four factors into account, including nine sub-indexes as follows: forest coverage (\%) (FC), annual primary energy (total primary energy production per year quadrillion BTU) (TPEP), renewable internal freshwater resource per capita $\left(\mathrm{m}^{3}\right)(\mathrm{RIFR})$, gross domestic product per capita ( GDP per capita US\$), the prevalence of malnutrition (PM \%), school enrollment, tertiary (\% gross) (SET)[2], peace index[3], life expectancy at birth year (LEB year), proportion of population using improved drinking-water sources (PPUIDS\%)[4]. Above-mentioned nine indexes, malnutrition prevalence and peace index are negatively correlated with the results of the evaluation, we call them cost indexes. Other indexes are positively correlated with the results, which we call efficiency indexes.

Steps of the Algorithm. We build the GA-BP Neural Network Model [5, 6] and carry out by the steps as following:

1. Generate initial population.

2. Train network and calculate individuals’ fitness. 


$$
f=\frac{1}{\sum_{i=1}^{n}\left(\hat{y}_{i}-y_{i}\right)^{2}}
$$

3. If Generation \$Max Generation, turn to step 4; otherwise, turn to step 5.

4. Genetic Manipulation: selection, crossover, mutation

5. Select the best individual then decode for the BP neural network.

6. Train the BP neural network.

7. If it meets the termination of training conditions, turn to step 8; otherwise, turn to step 6.

8. Use the trained network to test and evaluate.

Parameters. Main parameters of the algorithm: 1) BP neural network structure design: the input layer nodes is 9 , the output layer nodes is 1 , the hidden layer nodes $n$ is determined by the formula (2)

$$
n=\sqrt{n_{i}+n_{o}}+d
$$

Where $n_{i}$ is the number of input nodes, $n_{o}$ is the number of output nodes, $d$ is a constant range of $0 \sim 10$.Ultimately, we determine the value of $n$ equals 8, Topology of BP neural network is 9-8-1. 2) Parameters of GA: Population scale 200, Max generation 500.

\section{Planning making}

Situation Analysis. To evaluate Nepal's situation, we chose 10 countries having complete data as samples. All data about the indexes is in the Table 1.

Table 1 Statistics of ten countries (2012)

\begin{tabular}{lcc|cc|c|c|c|cc}
\hline & \multicolumn{3}{c}{ NR } & \multicolumn{2}{c|}{ CES } & \multicolumn{3}{c}{ HR } & \multicolumn{3}{c}{ LE } \\
& FC/\% & RIFR/m & TPEP/QBTU & GDP/US\$ & PM/\% & SET/\% & LEB/year & PPU/\% & PI \\
\hline Guinea & 26.3 & 19736 & 0.005 & 493.5 & 18.2 & 10 & 55 & 52 & 2.272 \\
Senegal & 43.6 & 1880 & 0.004 & 102.3 & 13.9 & 8 & 63 & 60 & 2.061 \\
Madagascar & 21.4 & 15116 & 0.007 & 445 & 31.2 & 4 & 64 & 29 & 2.124 \\
Nepal & 25.4 & 7214 & 0.031 & 699.1 & 12.1 & 14 & 68 & 66 & 2.001 \\
Cambodia & 55.7 & 8113 & 0 & 945.5 & 16.9 & 15 & 71 & 22 & 2.207 \\
Haiti & 3.6 & 1279 & 0.002 & 775.5 & 50 & 2 & 62 & 61 & 2.179 \\
Island & 1.4 & 530064 & 0.165 & 44221.7 & 0 & 82 & 83 & 100 & 1.113 \\
Switzerland & 31.6 & 5052 & 0.63 & 83295.3 & 0 & 56 & 82 & 100 & 1.349 \\
Austria & 47.3 & 6524 & 0.55 & 48348.2 & 0 & 72 & 80 & 100 & 1.337 \\
Colombia & 54.3 & 47585 & 4.506 & 7763 & 14.9 & 45 & 73 & 88 & 2.625 \\
\hline
\end{tabular}

Initially, we set the level of sustainable development 12 ranks, corresponding model output of 1-12 scores. After establishing the model, we solve the problem by MATLAB. The result of our model is showed in Table 2 .

Table 2 Result of our model

\begin{tabular}{llllll}
\hline Country & Guinea & Senegal & Madagascar & Nepal & Cambodia \\
\hline Score & 3.578312 & 3.770568 & 3.32912 & 3.92895 & 4.084474 \\
Grade & II & II & II & II & II \\
\hline Country & Haiti & Island & Switzerland & Austria & Colombia \\
\hline Score & 3.145684 & 10.78381 & 10.24347 & 11.348 & 8.418741 \\
Grade & II & IV & IV & IV & III \\
\hline
\end{tabular}

The situation is that: Nepal is part of Grade II countries. The status of sustainable development of Nepal is imperative

Plan making. In order to realize the growth speed of Nepal, we use Regression Analysis 
Prediction Method (RARM) to predict the nine indexes of sustainability in the future twenty years as a step of five years with no assistance. And we found that weak infrastructure, shortage of natural resources and backward agricultural are all the main factors to restrict Nepal's sustainable development. According to the prediction and analysis, we conclude that Nepal cannot achieve sustainable development goals in a short time in the absence of assistance. In order to improve the grade of sustainable development in Nepal, we draw up a 20-year sustainability plan as follows: 1 . In early period, provides food assistance such as rice to eradicate hungry. Besides, promote the intensive agriculture, liberate the rural labor force and improve the level of agricultural production; 2 . Take the advantage of labor cost to develop labor-intensive light industries such as garment production, absorb a lot of unemployment and labor force unemployed. Increase per capita income and government revenue; 3. Develop hydropower to solve the problem of electricity shortage; 4 . Improve the proportion of population using improved drinking-water sources by the gradual establishment of a modern water supply system; 5. Invest to construct the tourism infrastructure, improve the level of tourism services, excavate the value of spectacular landscape and diverse, exotic cultures, increase tourism revenue; 6 . Government and ICM invest to educate together, and set up higher education, that is advantage of improving the quality and development of high value-added high-tech industries; 7. Promote high-tech industry, e.g., IT industry; 8. Invest in health care facilities and try to increase life expectancy.

\section{Results evaluating}

Development goals. In order to measure the impact of the program on the level of sustainable development in Nepal, we set reasonable development goals showed in Table 3.

Table 3 Values of indexes in 2032

\begin{tabular}{lccccc}
\hline \multicolumn{3}{c}{ NR } & \multicolumn{2}{c}{ CES } \\
\hline Year & FC/\% & RIFR/m m $^{3}$ & TPEP/QBTU & GDP/US\$ & PM/\% \\
2032 & 25.3645 & 7213.994 & 0.05 & 2796.300001 & 0.001 \\
\hline \multicolumn{3}{c}{ LE } & HR & \\
\hline Year & LEB/year & PPUMDS/\% & PI & SET/\% \\
2032 & 75 & 90 & 1.8 & 28.9806 \\
\hline
\end{tabular}

Results analyzing. From Table 3 we can draw conclusions as follows : 1 . Natural Resources are basically invariant, which means we develop economy without sacrificing the environment; 2 . GDP per capita is four times that in 2012; 3. Average annual growth rate is $7.18 \%$, and the speed of development is fast; 3 . Malnutrition rate is $0.001 \%$, which implies that we eliminate hunger basically; 4. Enrollment in higher education reaches to $28.98 \%$, which is twice in 2012; 5. The proportion of people drinking clean water reaches to $90 \%$, and LEB rises to 75 years old; 6 . Improving people's living standards eases internal contradictions, and PI reduces to 1.8.

Results comparison. All the indexes we set changes uniformly according to a fixed rate of change. We get the indexes data at a step of five years by this means. We will put data into the GA-BP model to get the sustainability measure and plot a curve. Then we compare the curve with the unplanned one in Fig.1. 


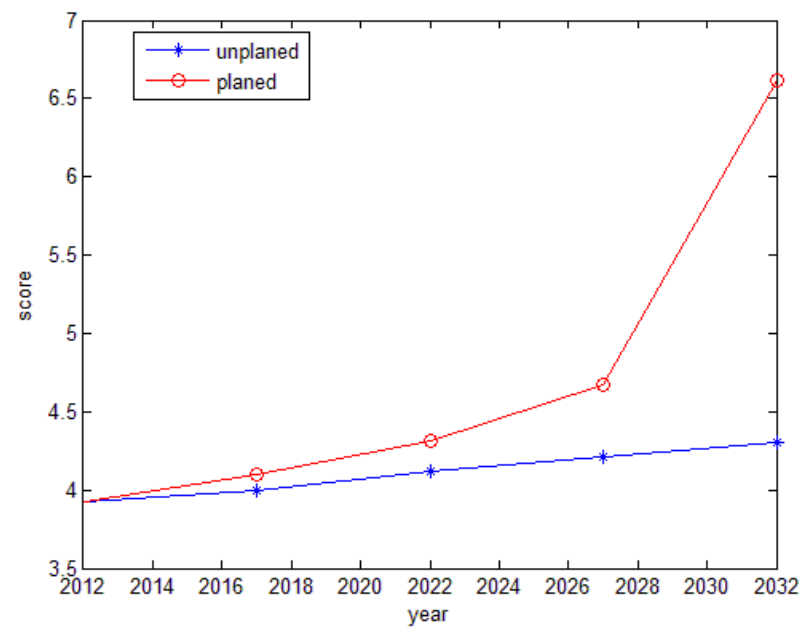

Fig.1 Sustainability measure curves

From Fig. 1 we can draw the following conclusions: 1. Nepal's sustainability measure will exceed 6 in about 2030, Nepal will be in Grade III at that time. We think it is our plan that makes Nepal more sustainable; 2. Without our plan, Nepal's sustainability measure increases very slowly, and is still an unsustainable country even after 20 years' development; 3 . The sustainability score increases linearly in a very low speed without our plan; 4. Implementing our plan, the sustainability score increases obviously. In conclusion, our plan can effectively improve the sustainability of Nepal.

\section{Summary}

We select nine indexes to build a GA-BP neural network model to evaluate the sustainability of country. We analyzed Nepal's situation by using our model. Then we consider the trends of indexes, Nepal's development status and national policies comprehensively, and draw up a 20-year plan for Nepal's development. The result indicates that our plan improves the sustainability of Nepal greatly.

\section{References}

[1] Information on http://siteresources.worldbank.org/INTEEI/ 214578-1110886258964/ 20748034/ All. pdf

[2] Information on http://data.worldbank.org.cn/country/nepal

[3] Information on https://zh.wikipedia.org/wiki/ global peace index

[4] Information on http://gamapserver.who.int/gho/interactive_charts/mdg7/ atlas.html? indicator= i2\&date $=2012$

[5]Xiaolong Yang, Xisong Liu. An Evaluation of Sustainable Development of Oil and Gas Resource Based on Process Neural Networks [J].JOURNAL OF HARBIN INSTITUTE OF TECHNOLOGY SOCIAL SCIENCES EDITION, 2006

[6]Zhengjun Liu, Aixia Liu, Changyao Wang .Evolving neural network using real coded genetic algorithm (GA) for multispectral image classification 2004 